\title{
Electronic materials
}

\section{Formation mechanism and thermoelectric properties of $\mathrm{CaMnO}_{3}$ thin films synthesized by annealing of $\mathrm{Ca}_{0.5} \mathrm{Mn}_{0.5} \mathrm{O}$ films}

Erik Ekström ${ }^{1, *}$ (D) , Arnaud le Febvrier ${ }^{1}$ (D), Daniele Fournier ${ }^{2}$ (D), Jun Lu $^{1}$ (D), Vladimir-Lucian Ene V $^{1,3}$ (D), Ngo Van Nong ${ }^{4}$ (1) Fredrik Eriksson ${ }^{1}$ (1) Per Eklund $^{1}$ (D), and Biplab Paul ${ }^{1, *}$ (i)

\footnotetext{
${ }^{1}$ Thin Film Physics Division, Department of Physics, Chemistry and Biology (IFM), Linköping University, 58183 Linköping, Sweden

${ }^{2}$ CNRS, Institut des NanoSciences de Paris, UMR 7588, Sorbonne Université, 75005 Paris, France

${ }^{3}$ Department of Oxide Materials and Nanomaterials, National Center for Micro and Nanomaterials, Faculty of Applied Chemistry and Material Science, University Politehnica of Bucharest, 60042 Bucharest, Romania

${ }^{4}$ Department of Energy Conversion and Storage, Technical University of Denmark, Risø Campus, Fredriksborgsvej 399, Building 779, 4000 Roskilde, Denmark
}

Received: 11 December 2018 Accepted: 27 February 2019 Published online:

7 March 2019

(C) The Author(s) 2019

\begin{abstract}
A two-step synthesis approach was utilized to grow $\mathrm{CaMnO}_{3}$ on $\mathrm{M}-$-, R- and $\mathrm{C}$-plane sapphire substrates. Radio-frequency reactive magnetron sputtering was used to grow rock-salt-structured ( $\mathrm{Ca}, \mathrm{Mn}) \mathrm{O}$ followed by a 3-h annealing step at $800{ }^{\circ} \mathrm{C}$ in oxygen flow to form the distorted perovskite phase $\mathrm{CaMnO}_{3}$. The effect of temperature in the post-annealing step was investigated using x-ray diffraction. The phase transformation to $\mathrm{CaMnO}_{3}$ started at $450{ }^{\circ} \mathrm{C}$ and was completed at $550{ }^{\circ} \mathrm{C}$. Films grown on R- and C-plane sapphire showed similar structure with a mixed orientation, whereas the film grown on M-plane sapphire was epitaxially grown with an out-of-plane orientation in the [202] direction. The thermoelectric characterization showed that the film grown on M-plane sapphire has about 3.5 times lower resistivity compared to the other films with a resistivity of $0.077 \Omega \mathrm{cm}$ at $500{ }^{\circ} \mathrm{C}$. The difference in resistivity is a result from difference in crystal structure, single orientation for M-plane sapphire compared to mixed for R- and C-plane sapphire. The highest absolute Seebeck coefficient value is $-350 \mu \mathrm{V} \mathrm{K}^{-1}$ for all films and is decreasing with temperature.
\end{abstract}




\section{Introduction}

Materials for thermoelectric generation are widely researched due to their capability to convert waste heat into electricity [1]. They have no moving parts and do not require any chemical reactions to operate which make them ideal for waste heat recovery. However, the most utilized thermoelectric modules are based on toxic and rare materials such as tellurium [2]. In addition, there are issues with chemical stability and low oxidation resistance at elevated temperatures. Oxides are therefore promising materials due to their high chemical stability and good oxidation resistance, and an additional advantage is that they are largely based on abundant and low-tomoderate cost materials. $\mathrm{Ca}_{3} \mathrm{Co}_{4} \mathrm{O}_{9}$ is a good candidate as a p-type thermoelectric material with a reported dimensionless figure of merit $\mathrm{ZT}=\sigma S^{2} T$ $K^{-1}$ around unity near $1000 \mathrm{~K}[3,4]$, where $\sigma, S$, $T$ and $K$ are the electrical conductivity, Seebeck coefficient, absolute temperature and thermal conductivity, respectively. To realize full oxide modules, the n-type oxides need improvement to achieve similar ZT as $p$-type oxides. The most investigated n-type thermoelectric materials are $\mathrm{CaMnO}_{3}, \mathrm{ZnO}$, $\mathrm{SrTiO}_{3}$ and $\mathrm{In}_{2} \mathrm{O}_{3}$, although these materials have so far shown only modest ZT values [5-7]. The perovskite $\mathrm{CaMnO}_{3}$ suffers from low electric conductivity and relatively high thermal conductivity, yielding low ZT. In the $\mathrm{CaMnO}_{3}$ system, the best ZT value reported is 0.32 for $\mathrm{Nb}$-doped $\mathrm{CaMnO}_{3}$ [8]. However, $\mathrm{CaMnO}_{3}$ can be a promising n-type candidate if the power factor $\left(\sigma S^{2}\right)$ is enhanced by optimal doping, since for high output power from a thermoelectric device the power factor is more important than the efficiency [9, 10], especially, in thin films for low-power applications.

For thin film growth of oxide materials, both chemical, e.g., chemical vapor deposition (CVD) [11, 12], chemical solution deposition (CSD) [13-16], and physical methods, e.g., physical vapor deposition (PVD) [17-19], have been reported. CVD exhibits a high growth rate with a high film uniformity, but high processing temperatures combined with byproducts that are generally toxic, explosive and corrosive in nature limit the technique. CSD is a fast and cheap method for growing films. Magnetron sputtering is a versatile PVD method and can be suitable for industrial upscaling. However, growing oxide thin films is a challenge which can be handled in several different ways. A few options are oxide targets sputtered in RF mode, metallic target using reactive gas operated in poisoned mode using RF or pulsed DC or metallic targets using reactive gas operated in metallic mode. Using oxide targets or running metal targets in poisoned mode results in slow growth rates. Running the system in metallic mode usually results in under stoichiometry of oxygen in the grown film. The optimal process parameters, where high deposition rates combined with desired stoichiometry are achieved, are often in a narrow window between metallic and poison mode. Careful process control is needed to remain in this narrow window [20].

In this study, we report a growth method which circumvents the above-mentioned problems for $\mathrm{CaMnO}_{3}$ thin films by a modified sputtering technique using a two-step sputtering/annealing technique [21-23] to maintain high deposition rates keeping the stoichiometry of the films. First, singlephase cubic $(\mathrm{Ca}, \mathrm{Mn}) \mathrm{O}$ thin films are deposited by cosputtering from elemental metallic targets of $\mathrm{Ca}$ and $\mathrm{Mn}$ in an oxygen-containing environment. Followed by annealing in air with additional oxygen to form the final phase of perovskite $\mathrm{CaMnO}_{3}$. This has the benefit of a high deposition rate, since the sputtering yield from metallic targets is always higher than that from the respective oxide targets. An additional advantage is that it allows perfect control of the composition of the films by controlling the target power. The phase transformation mechanism, from initial cubic $(\mathrm{Ca}, \mathrm{Mn}) \mathrm{O}$ phase to the final perovskite $\mathrm{CaMnO}_{3}$ phase, has been studied. Evaluation of the thermoelectric properties of the films is performed in terms of their power factor.

\section{Experimental details}

( $\mathrm{Ca}, \mathrm{Mn}) \mathrm{O}$ thin films were deposited onto $\mathrm{Al}_{2} \mathrm{O}_{3}$ (0001, C-plane), (11̄02, R-plane) and (1100, M-plane) substrates from elemental Ca $(99.5 \%$ purity) and elemental Mn (99.9\% purity) targets. Prior to deposition, the substrates were cleaned in an ultrasonic bath in acetone followed by isopropanol for $10 \mathrm{~min}$ each. The vacuum chamber at $4 \times 10^{-8}$ torr base pressure is described elsewhere [24]. Oxygen and argon were used as sputtering gases at a flow ratio of $\mathrm{O}_{2}\left(\mathrm{O}_{2}+\mathrm{Ar}\right)^{-1}=1.5 \%$ resulting in a total sputtering 
gas pressure of $0.27 \mathrm{~Pa}$. The substrate was kept for $10 \mathrm{~min}$ at $400{ }^{\circ} \mathrm{C}$ prior a 30 -min deposition resulting in film thicknesses around $250 \mathrm{~nm}$. The two magnetrons used unbalanced magnetic field configurations that were coupling to each other, and both were operated in RF mode at a power of $60 \mathrm{~W}$. The substrate table was kept electrically isolated from ground. The $\mathrm{Ca} / \mathrm{Mn}$ ratio was determined using energy-dispersive spectroscopy (EDS) in a scanning electron microscope (SEM, LEO Gemini 1550, Zeiss) at different regions of each sample.

The post-deposition ex situ annealing study was performed in a tube furnace in an air with $\mathrm{O}_{2}$ gas flowing atmosphere. The study was performed in steps where prior to sample insertion, the temperature of the furnace was stabilized at set temperature. The sample was removed from the furnace when it reached the intended annealing temperature. Prior to x-ray diffraction (XRD) measurements, the sample cooled down to room temperature. This process was repeated for increasingly higher temperature from $400{ }^{\circ} \mathrm{C}$ to $1000{ }^{\circ} \mathrm{C}$. The post-deposition annealing for the samples investigated more in depth was based on the ex situ annealing study, and $800{ }^{\circ} \mathrm{C}$ for $3 \mathrm{~h}$ was used at the same gas condition as in the ex situ annealing study.

XRD $\theta-2 \theta$ measurements were performed using a Philips PW1710 powder diffractometer with a copper anode source $\left(\mathrm{Cu} \mathrm{K} \mathrm{K}_{\alpha} \lambda=1.54 \AA\right.$ ), operated at $40 \mathrm{kV}$ and $40 \mathrm{~mA}$. A Ni filter was used directly after the X-ray source to remove $\mathrm{Cu} \mathrm{K}$. A $0.5^{\circ}$ divergence slit was positioned after the Ni filter. In the diffracted beam path, a 2-mm antiscatter slit, a $0.5^{\circ}$ receiving slit, a curved Ge-crystal monochromator and a proportional Xe-gas-filled detector to detect the intensity were used.

The temperature-dependent in-plane electrical resistivity and Seebeck coefficient were simultaneously measured using an ULVAC-RIKO ZEM3 system in a low-pressure helium atmosphere. The instrumental error is less than $7 \%$.

Samples for transmission electron microscopy (TEM) were prepared by ion beam milling. For crosssectional TEM, two pieces of the sample were glued together face-to-face and clamped with a Ti grid and then polished down to $50 \mu \mathrm{m}$ thickness. Finally, the polished sample was ion-milled in a Gatan precision ion polishing system at an $\mathrm{Ar}+$ energy of $5 \mathrm{kV}$ and a gun angle of $5^{\circ}$, with a final polishing step at $2 \mathrm{kV}$ $\mathrm{Ar}+$ energy. The TEM analysis was performed using a FEI Tecnai G2 TF20 UT instrument with a field emission gun operated at $200 \mathrm{kV}$ and with a point resolution of $1.9 \AA$.

Thermal conductivity of the films was obtained using modulated thermoreflectance microscopy (MTRM). In brief, a pump beam at $532 \mathrm{~nm}$ delivered by a Cobolt MLD laser, intensity modulated by an acousto-optical modulator at a frequency $\mathrm{f}$, is focused on the surface of the sample with an objective lens (N.A. $=0.5)$. In order to prevent effects from possible changes in the optical properties versus the $\mathrm{Mn}$ concentration, the layers were covered by a $250-\mathrm{nm}$ gold film, this top layer ensuring a heat source located at the surface. Then, thermal waves are excited in the sample and monitored by the reflectivity surface change recorded around the pump location by another focused laser beam. We use a 488-nm Oxxius laser to maximize the probe sensitivity to the thermal field in the gold cap layer. A photodiode and a lockin amplifier record the AC reflectivity component, in a frequency range between $1 \mathrm{kHz}$ and $1 \mathrm{MHz}$. Finally, the amplitude and phase experimental profiles were fitted according to a standard Fourier diffusion law to extract the thermal conductivity of the $\mathrm{CaMnO}_{3}$ films [25-28]. More details on the procedure of fit and extraction of the thermal conductivity of the film with a low thermal conductivity layer in between the gold and sapphire substrate can be found elsewhere [29].

\section{Results and discussion}

\section{As-deposited films}

Figure 1 shows $\theta-2 \theta$ x-ray diffractograms of as-deposited $\mathrm{Ca}_{0.5} \mathrm{Mn}_{0.5} \mathrm{O}$ films, cubic Fm-3m space group, grown on $\mathrm{M}-$, $\mathrm{R}$ - and $\mathrm{C}$-plane sapphire substrate. The XRD patterns matches the ICDD file for $\mathrm{Ca}_{0.559-}$ $\mathrm{Mn}_{0.441} \mathrm{O}$ [ICDD file \#01-077-2373], but with slight peak shifts. These peak shifts and the corresponding variation of lattice parameters might have been either from developed stress in the films or due to the slight variation of Ca-to-Mn ratio in the films within the uncertainty limit of EDS. The lattice parameters for pure $\mathrm{CaO}$ and $\mathrm{MnO}$, both in cubic $\mathrm{Fm}-3 \mathrm{~m}$ space group, are reported to be $4.8106 \AA$ (ICDD file 00-0371497) and 4.4460 $\AA$ (ICDD file 01-075-6876), respectively, and from Vegard's law, the lattice parameter of $\mathrm{Ca}_{0.5} \mathrm{Mn}_{0.5} \mathrm{O}$ is calculated to be $4.628 \AA$. From XRD 


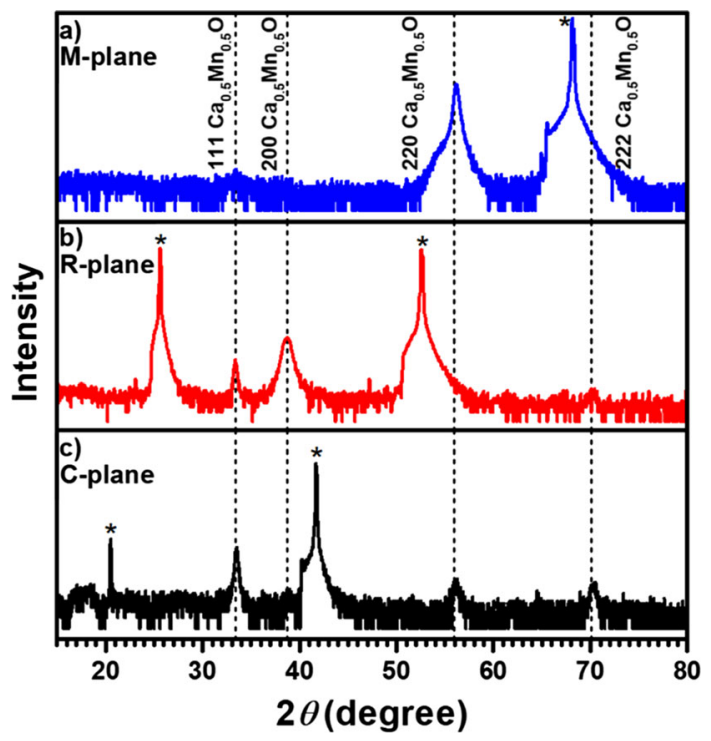

Figure $1 \theta-2 \theta$ x-ray diffractogram of as-deposited $\mathrm{Ca}_{0.5} \mathrm{Mn}_{0.5} \mathrm{O}$ films grown on M-, R- and C-plane sapphire, corresponding to ac, respectively. The substrate peaks are marked with a star.

peak positions, the lattice parameters are calculated to be $4.65 \AA, 4.64 \AA$ and $4.63 \AA$, for the films grown on $\mathrm{R}$-, $\mathrm{M}$ - and C-plane sapphire, respectively, which closely match with the calculated value for $\mathrm{Ca}_{0.5} \mathrm{Mn}_{0.5} \mathrm{O}$.

The XRD pattern for film grown on M-plane sapphire, shown in Fig. 1a, shows a peak corresponding to the 220 peak of rock-salt-structured $\mathrm{Ca}_{0.5} \mathrm{Mn}_{0.5} \mathrm{O}$ and the substrate peak $30 \overline{3} 0$. The film grown on $\mathrm{R}-$ plane sapphire substrate, shown in Fig. 1b, shows strong reflections from the (111) and (200) planes and a weak reflection from the (222) planes of $\mathrm{Ca}_{0.5-}$ $\mathrm{Mn}_{0.5} \mathrm{O}$. The $01 \overline{1} 2$ and $02 \overline{2} 4$ peaks from the sapphire substrate are also seen. The film grown on C-plane sapphire substrate, shown in Fig. 1c, shows 111, 220 and 222 peaks from $\mathrm{Ca}_{0.5} \mathrm{Mn}_{0.5} \mathrm{O}$ along with the substrate 0006 peak.

Figure $2 \mathrm{a}$ shows the TEM images of the as-deposited $\mathrm{Ca}_{0.5} \mathrm{Mn}_{0.5} \mathrm{O}$ films grown on M-plane sapphire. The high-resolution (HR) TEM image in Fig. $2 b$ shows that the rock-salt-structured $(\mathrm{Ca}, \mathrm{Mn}) \mathrm{O}$ film is epitaxially grown on M-plane sapphire substrate, with domains as usual for rock-salt-structured materials on this surface of $\alpha-\mathrm{Al}_{2} \mathrm{O}_{3}$. The rock-salt structure is closely related to the hexagonal structured $\alpha-\mathrm{Al}_{2} \mathrm{O}_{3}$ where the difference in structure can be explained by the stacking order (A-B-C for $(\mathrm{Ca}, \mathrm{Mn}) \mathrm{O}$ and $\mathrm{A}-\mathrm{B}-\mathrm{A}$ for $\left.\alpha-\mathrm{Al}_{2} \mathrm{O}_{3}\right)$. Because of the close relation between these two structures, it is well

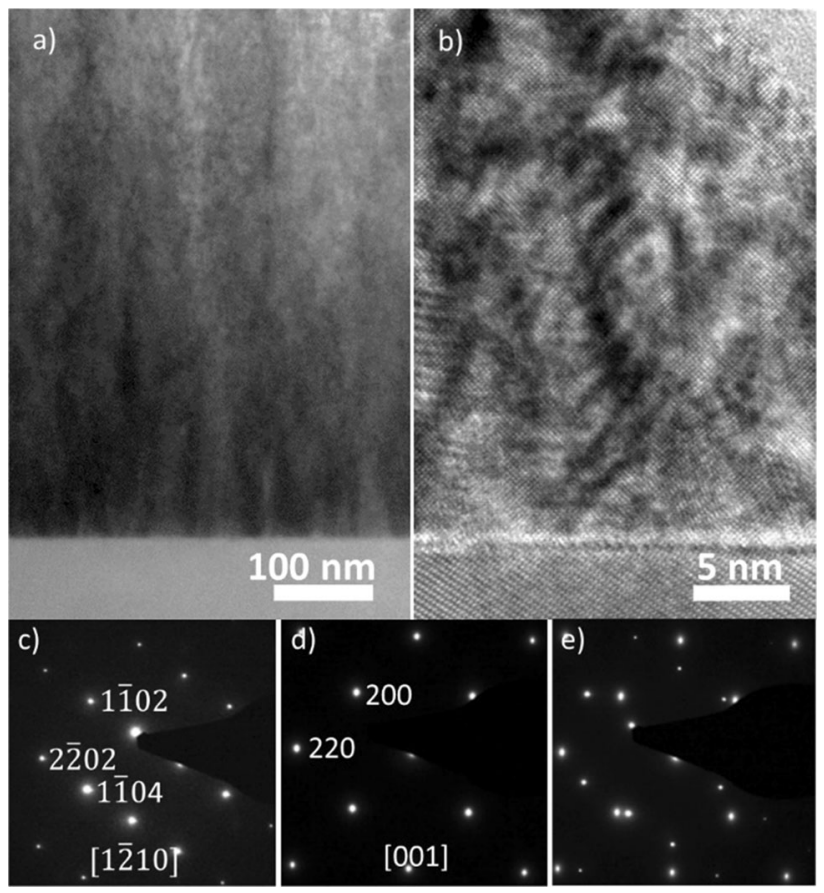

Figure 2 TEM images of as-deposited films on M-plane sapphire substrate where $\mathbf{a}$ and $\mathbf{b}$ are low- and high-resolution TEM images. $\mathbf{c}-\mathbf{e}$ are SAED pattern of substrate, film and substrate + film, respectively.

known how these two materials are grown on each other, a typical example of this is shown by Eklund et al. [30]. The film is single phase with the crystallographic relationship $\mathrm{Ca}_{0.5} \mathrm{Mn}_{0.5} \mathrm{O}$ (220) I। $\mathrm{Al}_{2} \mathrm{O}_{3}$ (1100) and $\mathrm{Ca}_{0.5} \mathrm{Mn}_{0.5} \mathrm{O}$ [001] । I $\mathrm{Al}_{2} \mathrm{O}_{3}$ [121210], as confirmed by the selected area electron diffraction (SAED) patterns in Fig. 2c, d. Figure $3 b$ shows the TEM images of the as-deposited $\mathrm{Ca}_{0.5} \mathrm{Mn}_{0.5} \mathrm{O}$ films grown on C-plane sapphire. The films grown on C-plane sapphire are polycrystalline, which is also the case for the films grown on R-plane sapphire (not shown here). Figure 3c-e shows the SAED patterns of the C-plane sapphire where (d), corresponding to the film, shows elongated spots (almost forming rings) confirming the polycrystalline nature of the film.

In summary, the XRD and TEM results show that the as-deposited films grown on M-plane sapphire are phase-pure containing epitaxial domains with a well-defined microstructure. Films grown on C- and R-plane sapphire show similar structural properties where both are polycrystalline with less well-defined microstructure than those grown on M-plane sapphire. 


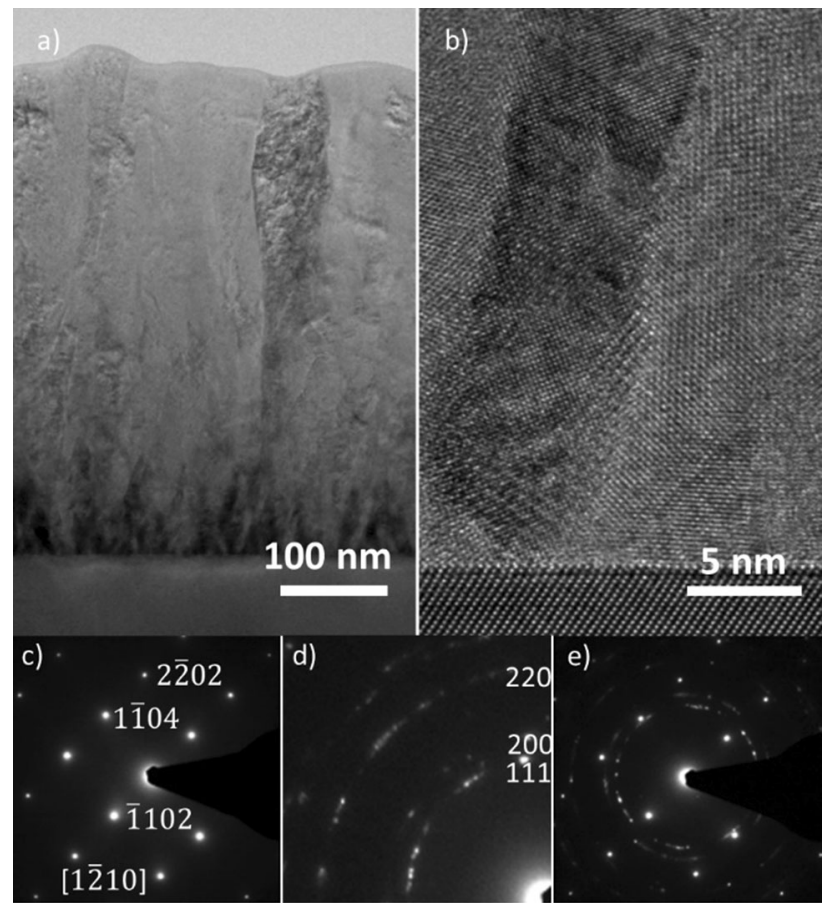

Figure 3 TEM images of as-deposited films on C-plane sapphire substrate where $\mathbf{a}$ and $\mathbf{b}$ are low- and high-resolution TEM images. $\mathbf{c}-\mathbf{e}$ are SAED pattern of substrate, film and substrate + film, respectively.

\section{Phase transformation}

To study the phase transformation mechanism from initial $\mathrm{Ca}_{0.5} \mathrm{Mn}_{0.5} \mathrm{O}$ film to the final phase of perovskite $\mathrm{CaMnO}_{3}$, ex situ x-ray annealing was performed in air with $\mathrm{O}_{2}$ flowing at increasing temperature from $450{ }^{\circ} \mathrm{C}$ to $1000{ }^{\circ} \mathrm{C}$. Between each annealing step, the sample was cooled down to room temperature and measured using XRD. The general trend is similar for both samples, and Fig. $4 a, b$ shows the $\theta-2 \theta$ x-ray diffractograms from the annealing study for the films grown on $\mathrm{M}$ - and R-plane sapphire, respectively. Above $500{ }^{\circ} \mathrm{C}$, the phase transformation from Fm-3m to Pnma is almost complete, as the peak from rock-salt structure disappears and 101, 202, 121 and 242 peaks of $\mathrm{CaMnO}_{3}$ gradually appear at $2 \theta$ angles $23.83^{\circ}, 34.07^{\circ}, 48.90^{\circ}$ and $71.70^{\circ}$, respectively. With further increase in temperature, the peaks of $\mathrm{CaMnO}_{3}$ become more intense with gradual decrease in full width at half maximum (FWHM), which indicates the improvement of crystal quality with temperature. Pole figure analyses of the films annealed at $800{ }^{\circ} \mathrm{C}$ confirm the texture quality of the film (see figure S1 and S2 in
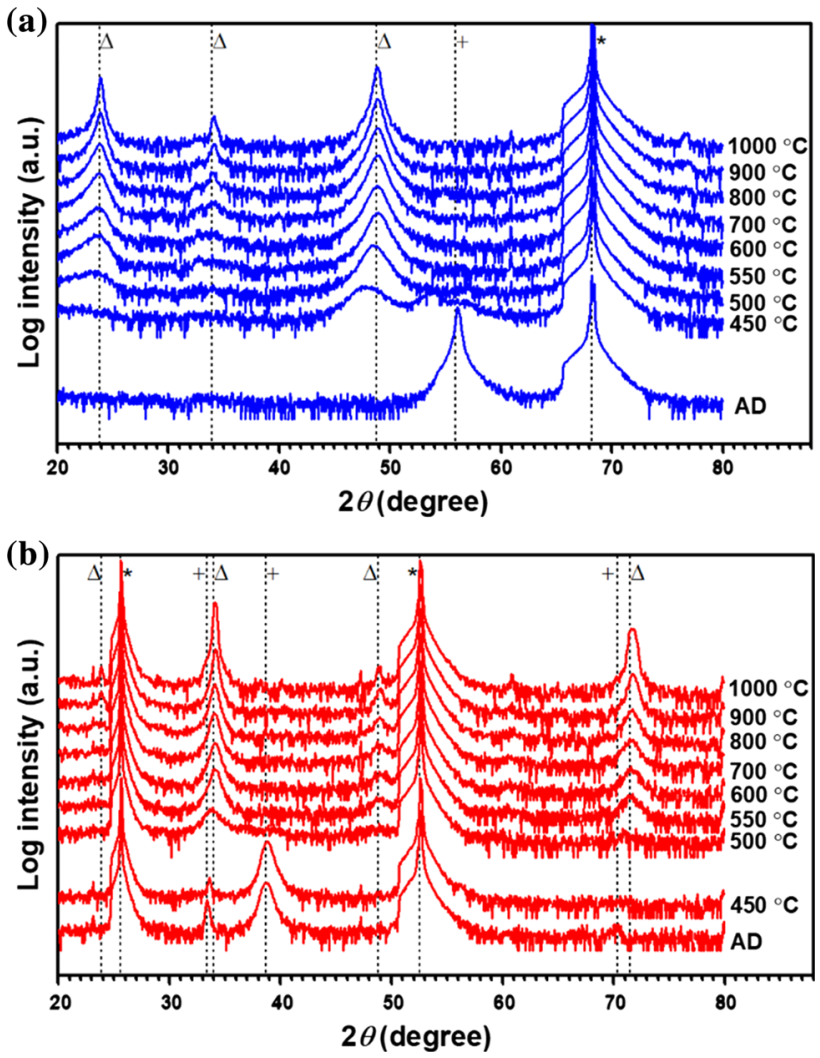

Figure $4 \theta-2 \theta$ x-ray diffractograms of $\mathrm{CaMnO}_{3}$ film grown on M-plane sapphire (a) and R-plane sapphire (b), annealed at different temperatures. Stars, triangles and plus-signs correspond to substrate (ICDD file 00-046-1212), $\mathrm{CaMnO}_{3}$ (Ref. [31] ICDD file 01-076-8574) and $\mathrm{Ca}_{0.5} \mathrm{Mn}_{0.5} \mathrm{O}$ (ICDD file 01-077-2373), respectively.

supplementary information). Above $800{ }^{\circ} \mathrm{C}$, the diffraction peaks shift to higher $2 \theta$ values, which implies macroscopic stress in the sample. Appearance of low intense peaks is also clear from Fig. 4a, b, which is attributed to the partial presence of secondary orientation in both the films on $\mathrm{M}$ - and R-plane sapphire substrates. The overall trend on films grown on R-plane sapphire is similar for films grown on C-plane sapphire (not shown here).

From the above study, it is clear that the annealing temperatures in the range $500-800{ }^{\circ} \mathrm{C}$ facilitate the formation of single-phase and singly oriented $\mathrm{CaMnO}_{3}$ films, and annealing temperature of $800{ }^{\circ} \mathrm{C}$ is favorable to produce films with a well-defined microstructure. 


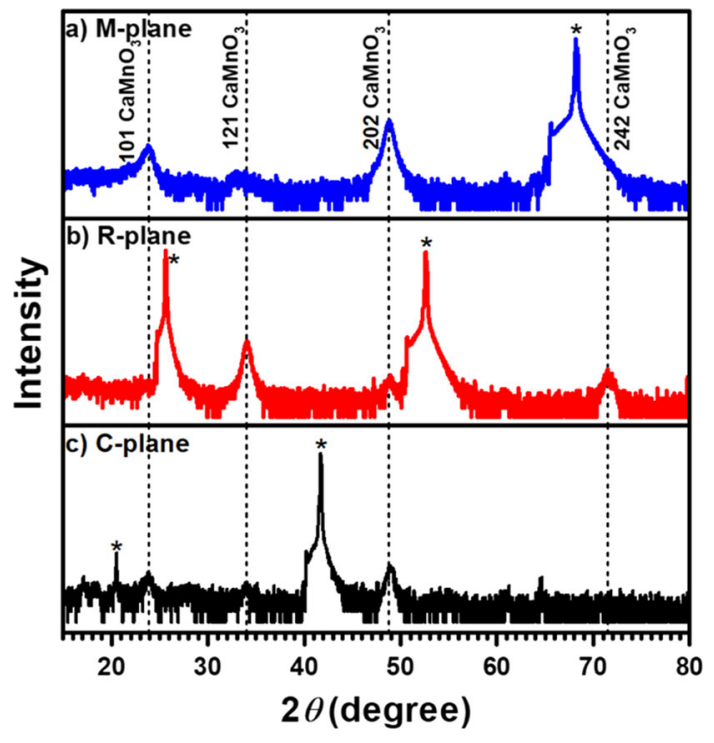

Figure $5 \theta-2 \theta$ x-ray diffractogram of annealed, at $800{ }^{\circ} \mathrm{C}$ for three hours, $\mathrm{CaMnO}_{3}$ films grown on $\mathrm{M}-$, R- and C-plane sapphire, corresponding to $\mathbf{a}-\mathbf{c}$, respectively. Peaks marked with a star are from the substrate (ICDD file 00-046-1212).

\section{Structure of post-annealed films}

Figure 5 shows the $\theta-2 \theta$ x-ray diffractograms of annealed $\mathrm{CaMnO}_{3}$ films grown on $\mathrm{M}-$, $\mathrm{R}-$ and C-plane sapphire. For M-plane sapphire (a), the film exhibits the 101 and 202 peaks from $\mathrm{CaMnO}_{3}$ and a minor contribution from a secondary (121) orientation as indicated by the low-intensity 121 peak. The films grown on R- and C-plane sapphire, (b) and (c), show the 121 and 242 peaks from $\mathrm{CaMnO}_{3}$ with a contribution from 202. The diffraction peaks match the bulk $\mathrm{CaMnO}_{3}$ in Ref. [31] (ICSD 01-076-8574) with, at most, a $0.2 \%$ difference in $2 \theta$ angle.

TEM images and diffraction patterns of annealed samples grown on M- and R-plane sapphire substrate are shown in Fig. $6 \mathrm{a}-\mathrm{d}$, respectively. The film grown on M-plane sapphire no longer shows the well-defined diffraction spots of the as-deposited film, but it is still highly textured with an out-of-plane (101) orientation. The film on M-plane sapphire has a single-phased structure with a relatively small amount of grains with secondary orientations forming throughout the films as seen in Fig. 6a. In contrast, the $\mathrm{CaMnO}_{3}$ film grown on R-plane sapphire is polycrystalline as seen in the SAED pattern, which is also typical for the films grown on C-plane sapphire, as expected given their starting microstructure before annealing.
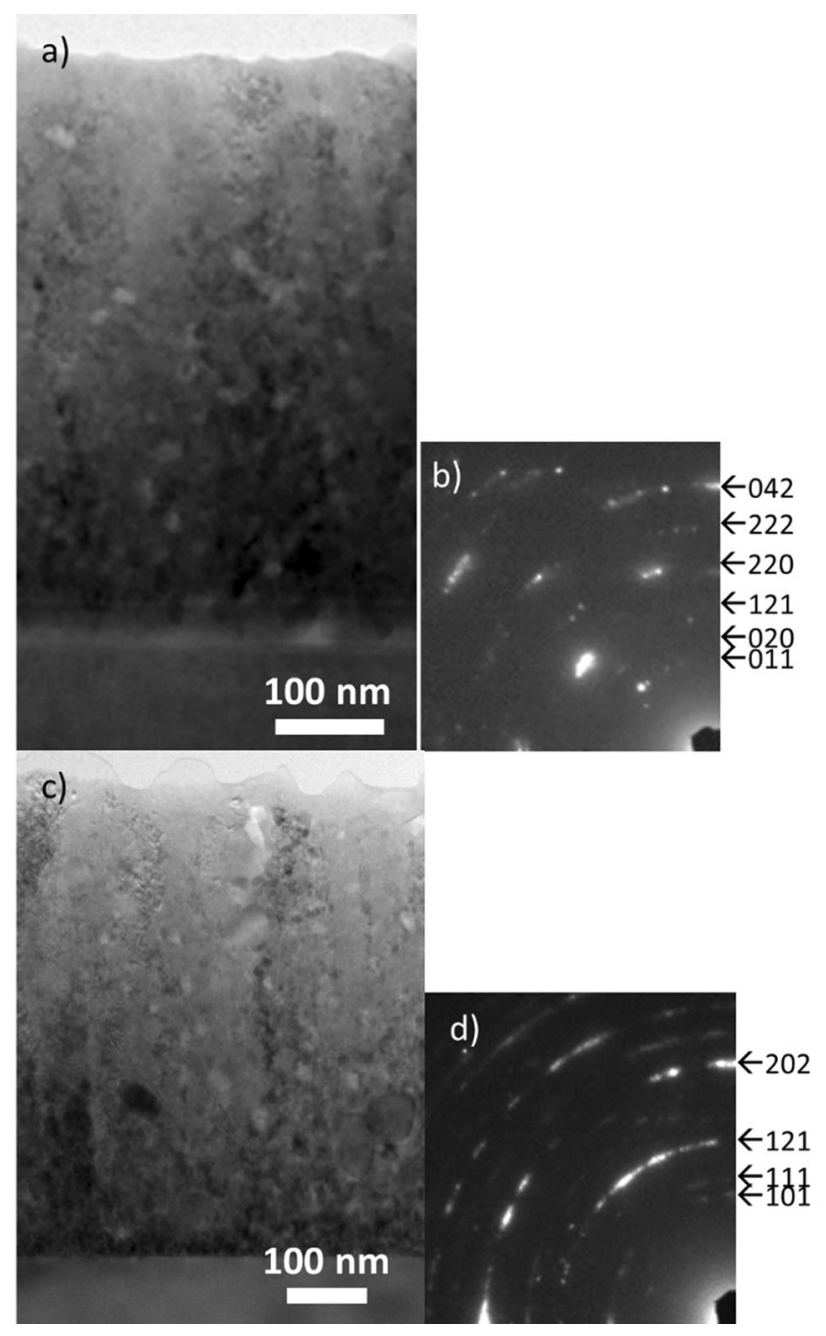

Figure 6 TEM image and SAED pattern of annealed film on M-plane sapphire (a) and (b) and R-plane sapphire (c) and (d).

\section{Thermoelectric properties}

The thermal conductivity measured at room temperature is tabulated in Table 1 and is in the same range as previously reported bulk values, $3.5 \mathrm{~W}$ $(\mathrm{mK})^{-1}, 4.1 \mathrm{~W}(\mathrm{mK})^{-1}$ and $2.8 \mathrm{~W}(\mathrm{mK})^{-1}$ [32-34].

Figure 7 shows the resistivity $(\rho)$ in $(\mathrm{a}), \ln (\sigma T)(\mathrm{b})$, Seebeck coefficient $(S)$ in (c) and power factor $\left(\sigma S^{2}\right)$ in

Table 1 Room-temperature thermal conductivity of annealed films

\begin{tabular}{ll}
\hline Sample & Thermal conductivity $(k)\left[\mathrm{W}(\mathrm{mK})^{-1}\right]$ \\
\hline M-plane & $2.3 \pm 0.2$ \\
R-plane & $5.2 \pm 0.5$ \\
C-plane & $4.5 \pm 0.5$ \\
\hline
\end{tabular}



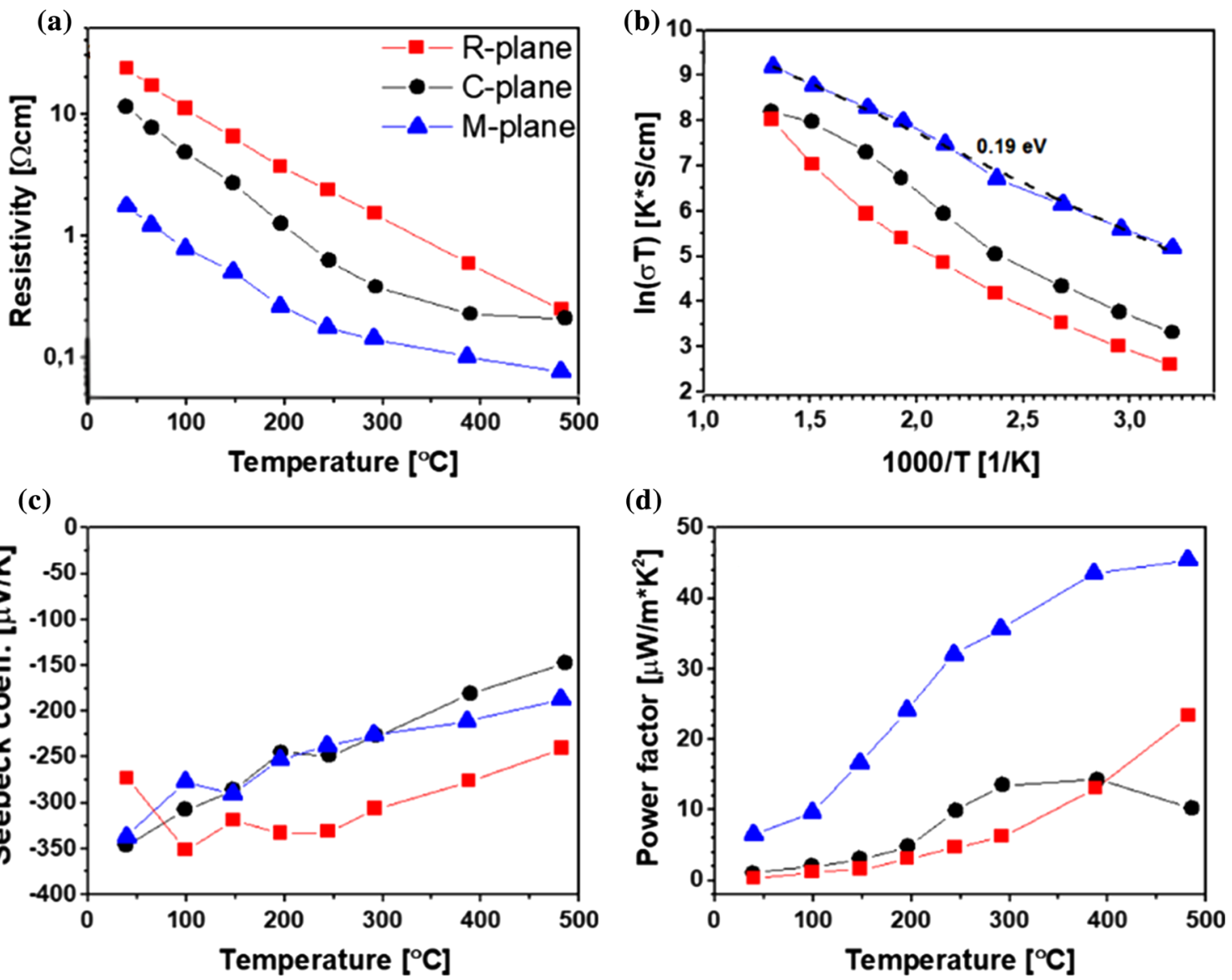

Figure 7 Resistivity, $\ln (\sigma T)$, Seebeck coefficient and power factor as a function of temperature are shown in a-d, respectively, for $\mathrm{CaMnO}_{3}$ films grown on $\mathrm{M}-\mathrm{R}$ - and C-plane sapphire.

(d) as a function of temperature for films grown on M-, R- and C-plane sapphire. The electrical resistivity ranges from $1.75 \Omega \mathrm{cm}$ at room temperature to $0.077 \Omega \mathrm{cm} \sim 500{ }^{\circ} \mathrm{C}$ for the film grown on M-plane sapphire, $23.40 \Omega \mathrm{cm}$ at room temperature to $0.25 \Omega \mathrm{cm}$ at $\sim 500{ }^{\circ} \mathrm{C}$ for R-plane sapphire and $11.33 \Omega \mathrm{cm}$ to $0.21 \Omega \mathrm{cm}$ for C-plane sapphire. The Seebeck coefficient is the highest for the film grown on R-plane sapphire substrate ranging from $-350 \mu \mathrm{V} \mathrm{K}^{-1}$ at room temperature to $-250 \mu \mathrm{V} \mathrm{K}-1$ at $500{ }^{\circ} \mathrm{C}$. The Seebeck values for the films grown on $\mathrm{C}$ - and $\mathrm{M}$-plane sapphire are similar and range from $-350 \mu \mathrm{V} \mathrm{K}^{-1}$ at room temperature to $-200 \mu \mathrm{V} \mathrm{K}^{-1}$ at $500{ }^{\circ} \mathrm{C}$. The decrease in the absolute value of the Seebeck coefficient, $|S|$, with temperature is attributed to the excitation of minority charge carriers [35]. In Fig. $7 \mathrm{~b}, \ln (\sigma T)$ vs $T^{-1}$ is plotted to determine the activation energy $E_{a}$ for the electrical conductivity following the Arrhenius formula, as shown in Eq. (1) and (2) [36].

$$
\begin{aligned}
& \sigma=\frac{A}{T} \exp \left(\frac{-E_{\mathrm{a}}}{k_{\mathrm{b}} T}\right) \\
& \ln (\sigma T)=\ln (A)-\frac{-E_{\mathrm{a}}}{k_{\mathrm{b}} T}
\end{aligned}
$$

Here, $\sigma, A, T$ and $k_{\mathrm{b}}$ are the electrical conductivity, a constant, the temperature and Boltzmann's constant, respectively. This equation describes a small polaron hopping model which is commonly used to describe electrical conductivity for $\mathrm{CaMnO}_{3}$ [37]. The Arrhenius plot in Fig. $7 \mathrm{~b}$ is linear in the whole temperature range for films grown on $\mathrm{M}$-plane sapphire and nonlinear above $200{ }^{\circ} \mathrm{C}$ for films grown on $\mathrm{R}$ - and $\mathrm{C}$-plane sapphire. The activation energy for film grown on M-plane sapphire is evaluated to $0.19 \pm 0.01 \mathrm{eV}$ from the slope in Fig. $7 \mathrm{~b}$. The nonlinear behavior in films grown on $\mathrm{R}$ - and C-plane sapphire has been observed in other studies [38]. The reason for the nonlinear behavior is unknown; however, Zhou et al. report an anomaly in the octahedral 
Table 2 Values from the literature (bulk) and this study on $\rho, S$ and $\sigma S^{2}$ at room temperature and $E_{\mathrm{a}}$

\begin{tabular}{lllll}
\hline Source & $\rho(\Omega \mathrm{cm})$ & $S\left(\mu \mathrm{V} \mathrm{K}^{-1}\right)$ & $\sigma S^{2}\left(\mu \mathrm{W} \mathrm{m}^{-1} \mathrm{~K}^{-2}\right)$ & $E_{\mathrm{a}}(\mathrm{eV})$ \\
\hline Zhu et al. [41] & 0.09 & -350 & 136 & - \\
Kabir et al. [34] & 0.12 & -350 & 100 & 0.05 \\
This work (m-plane) & 1.75 & -350 & 15 & 0.19 \\
Xu et al. [40] & 7.6 & -450 & 2.7 & - \\
Ohtaki et al. [32] & 10 & -450 & 2 & 0.16 \\
Huang et al. [33] & - & -550 & - & 0.17 \\
\hline
\end{tabular}

tilt angles in this temperature range which could explain the observed change in activation energy [39].

The power factor $\left(\sigma S^{2}\right)$ is the highest for the film grown on $\mathrm{M}$-plane sapphire reaching $45 \mu \mathrm{W} \mathrm{m} \mathrm{m}^{-1-}$ $\mathrm{K}^{-2}\left(500{ }^{\circ} \mathrm{C}\right)$, which is comparable to $\mathrm{Xu}$ et al. $\left(60 \mu \mathrm{W} \mathrm{m}{ }^{-1} \mathrm{~K}^{-2}\right.$ [40]) and Ohtaki et al. $\left(50 \mu \mathrm{W} \mathrm{m}^{-1-}\right.$ $\mathrm{K}^{-2}$ [32]) reported values on undoped $\mathrm{CaMnO}_{3}$ at room temperature. However, there are higher reported values from Kabir et al. $\left(140 \mu \mathrm{W} \mathrm{m}^{-1} \mathrm{~K}^{-2}\right.$ [34]) and $\mathrm{Zhu}$ et al. $\left(170 \mu \mathrm{W} \mathrm{m}{ }^{-1} \mathrm{~K}^{-2}\right.$ [41]). The highest power factor for our films is the film on M-plane sapphire which is due to its low electrical resistivity.

Some reported values in the literature for resistivity, Seebeck coefficient and power factor at room temperature and activation energy are tabulated in Table 2. All references in Table 2 use solid-state reaction (SSR) for synthesizing the $\mathrm{CaMnO}_{3}$ bulk samples. Huang et al. [33] report a resistivity value that is in the range of $10 \Omega \mathrm{cm}$. A trend is clearly visible. Higher resistivity results in both higher absolute Seebeck coefficient and activation energy. However, the reported values are rather different between studies and differ almost 100 times in the extreme case for resistivity. A possible explanation for these differences can be found by taking oxygen deficiency into consideration. Goldyreva et al. [42, 43] report that oxygen vacancies act as electron donors by creating $\mathrm{Mn}^{3+}$ from $\mathrm{Mn}^{4+}$. This change reduces, similarly too alloying with rare earth metals, resistivity, Seebeck coefficient and activation energy. Based on this, our films grown on M-plane sapphire are most likely deficient in oxygen as they have lower values in both resistivity and Seebeck compared to three of the listed references in Table 2. As the crystallinity is poorer for films grown on R- and C-plane sapphire, one should be careful to draw the same conclusion on these samples because the thermoelectric properties are likely heavily influenced by defects. From Table 2 and our discussion above, it is clear that oxygen vacancies are favorable for the performance of $\mathrm{CaMnO}_{3}$ as a thermoelectric material.

\section{Conclusion}

We have synthesized $\mathrm{CaMnO}_{3}$ thin films on sapphire using a two-step synthesis method. First, $(\mathrm{Ca}, \mathrm{Mn}) \mathrm{O}$ is deposited on sapphire substrates using RF reactive magnetron co-sputtering from elemental targets. Secondly, the as-deposited films are annealed to transform the films to orthorhombic (Pnma) structured $\mathrm{CaMnO}_{3}$. An annealing study showed that $\mathrm{CaMnO}_{3}$ is formed from $500{ }^{\circ} \mathrm{C}$ and $800{ }^{\circ} \mathrm{C}$ is favorable for the formation of a well-defined microstructure. The structural and thermoelectric properties on different sapphire substrates (M-, R- and C-plane) were evaluated. The effect of post-annealing temperature is also investigated.

Films grown on M-plane sapphire are epitaxially related to the substrate without any secondary orientation in the as-deposited state. After the annealing process, the film remains highly textured, in contrast to polycrystalline films grown on $\mathrm{C}$ - or $\mathrm{R}$ - plane sapphire. A film on M-plane sapphire exhibits a power factor of $45 \mu \mathrm{W} \mathrm{m}{ }^{-1} \mathrm{~K}^{-2}$ at $500{ }^{\circ} \mathrm{C}$.

\section{Acknowledgements}

The authors acknowledge the funding from the Swedish Foundation for Strategic Research (SSF) through the Future Research Leaders 5 program, the Swedish Research Council (VR) under Project No. 2016-03365, the Knut and Alice Wallenberg Foundation through the Wallenberg Academy Fellows program, the European Research Council under the European Community's Seventh Framework Programme (FP7 = 2007-2013) ERC Grant Agreement No. 335383, and the Swedish Government Strategic Research Area in Materials Science on 
Functional Materials at Linköping University (Faculty Grant SFO-Mat-LiU No. 2009 00971).

Electronic supplementary material: The online version of this article (https://doi.org/10.1007/s108 53-019-03496-7) contains supplementary material, which is available to authorized users.

Open Access This article is distributed under the terms of the Creative Commons Attribution 4.0 International License (http://creativecommons.org/ licenses/by/4.0/), which permits unrestricted use, distribution, and reproduction in any medium, provided you give appropriate credit to the original author(s) and the source, provide a link to the Creative Commons license, and indicate if changes were made.

\section{References}

[1] Bell LE (2008) Cooling, heating, generating power, and recovering waste heat with thermoelectric systems. Science 321:1457-1461

[2] Amatya R, Ram RJ (2012) Trend for thermoelectric materials and their earth abundance. $\mathrm{J}$ Electron Mater 41:1011-1019

[3] Shikano M, Funahashi R (2003) Electrical and thermal properties of single-crystalline $(\mathrm{Ca} 2 \mathrm{CoO} 3)(0.7) \mathrm{CoO} 2$ with a Ca3Co4O9 structure. Appl Phys Lett 82:1851-1853

[4] Koumoto K, Funahashi R, Guilmeau E, Miyazaki Y, Weidenkaff A, Wang YF, Wan CL (2013) Thermoelectric ceramics for energy harvesting. J Am Ceram Soc 96:1-23

[5] Fergus JW (2012) Oxide materials for high temperature thermoelectric energy conversion. J Eur Ceram Soc 32:525-540

[6] Ren GK, Lan JL, Zeng CC, Liu YC, Zhan B, Butt S, Lin YH, Nan CW (2015) High performance oxides-based thermoelectric materials. JOM 67:211-221

[7] Wang H, Su W, Liu J, Wang C (2016) Recent development of n-type perovskite thermoelectrics. J Materiomics 2:225-236

[8] Bocher L, Robert R, Aguirre MH, Malo S, Hebert S, Maignan A, Weidenkaff A (2008) Thermoelectric and magnetic properties of perovskite-type manganate phases synthesised by ultrasonic spray combustion (USC). Solid State Sci 10:496-501

[9] Liu W, Kim HS, Jie Q, Ren Z (2016) Importance of high power factor in thermoelectric materials for power generation application: a perspective. Scripta Mater 111:3-9
[10] Liu WS, Kim HS, Chen S, Jie Q, Lv B, Yao ML, Ren ZS, Opeil CP, Wilson S, Chu CW, Ren ZF (2015) n-type thermoelectric material $\mathrm{Mg} 2 \mathrm{Sn} 0.75 \mathrm{Ge} 0.25$ for high power generation. Proc Natl Acad Sci USA 112:3269-3274

[11] Ngamou PHT, Bahlawane N (2009) Chemical vapor deposition and electric characterization of perovskite oxides LaMO3 ( $\mathrm{M}=\mathrm{Co}, \mathrm{Fe}, \mathrm{Cr}$ and $\mathrm{Mn})$ thin films. J Solid State Chem 182:849-854

[12] Nilsen O, Rauwel E, Fjellvag H, Kjekshus A (2007) Growth of $\mathrm{La} 1-\mathrm{xCaxMnO} 3$ thin films by atomic layer deposition. J Mater Chem 17:1466-1475

[13] Feng C, Yang CH, Zhou YY, Geng FJ, Lv PP, Yao Q (2016) Substrate-dependent ferroelectric and dielectric properties of derived by chemical solution decomposition. J Alloys Compd 679:133-137

[14] Sakamoto W, Yamazaki H, Iwata A, Shimura T, Yogo T (2006) Synthesis and characterization of $\mathrm{BiFeO} 3-\mathrm{PbTiO} 3$ thin films through metalorganic precursor solution. Jpn J Appl Phys Part 1 Regul Pap Brief Commun Rev Pap 45:7315-7320

[15] Sharma S, Tomar M, Kumar A, Puri NK, Gupta V (2016) Photovoltaic effect in $\mathrm{BiFeO} 3 / \mathrm{BaTiO} 3$ multilayer structure fabricated by chemical solution deposition technique. J Phys Chem Solids 93:63-67

[16] Okuyucu H, Cinici H, Konak T (2013) Coating of nanosized ionically conductive $\mathrm{Sr}$ and $\mathrm{Ca}$ doped $\mathrm{LaMnO} 3$ films by sol-gel route. Ceram Int 39:903-909

[17] Flint CL, Grutter AJ, Jenkins CA, Arenholz E, Suzuki Y (2014) Magnetism in $\mathrm{CaMnO}_{3}$ thin films. J Appl Phys 115:17D712

[18] Jha P, Sands TD, Cassels L, Jackson P, Favaloro T, Kirk B, Zide J, Xu XF, Shakouri A (2012) Cross-plane electronic and thermal transport properties of p-type $\mathrm{La} 0.67 \mathrm{Sr} 0.33 \mathrm{MnO} / \mathrm{LaMnO} 3$ perovskite oxide metal/semiconductor superlattices. J Appl Phys 112:063714

[19] Ohta H, Sugiura K, Koumoto K (2008) Recent progress in oxide thermoelectric materials: p-type Ca3Co4O9 and n-type SrTiO3(-). Inorg Chem 47:8429-8436

[20] Ellmer K (2000) Magnetron sputtering of transparent conductive zinc oxide: relation between the sputtering parameters and the electronic properties. J Phys D-Appl Phys 33:R17-R32

[21] Paul B, Lu J, Eklund P (2017) Nanostructural tailoring to induce flexibility in thermoelectric $\mathrm{Ca} 3 \mathrm{Co} 4 \mathrm{O} 9$ thin films. ACS Appl Mater Interfaces 9:25308-25316

[22] Paul B, Schroeder JL, Kerdsongpanya S, Nong NB, Schell N, Ostach D, Lu J, Birch J, Eklund P (2015) Mechanism of formation of the thermoelectric layered cobaltate $\mathrm{Ca}_{3} \mathrm{Co}_{4} \mathrm{O}_{9}$ by annealing of $\mathrm{CaO}-\mathrm{CoO}$ thin films. Adv Electron Mater $1: 1400022$ 
[23] Paul B, Björk EM, Kumar A, Lu J, Eklund P (2018) Nanoporous Ca3Co4O9 Thin Films for Transferable Thermoelectrics. ACS Appl Energy Mater 1:2261-2268

[24] Trinh DH, Ottosson M, Collin M, Reineck I, Hultman L, Högberg H (2008) Nanocomposite Al2O3-ZrO2 thin films grown by reactive dual radio-frequency magnetron sputtering. Thin Solid Films 516:4977-4982

[25] Frétigny C, Duquesne J-Y, Fournier D, Xu F (2012) Thermal insulating layer on a conducting substrate. Analysis of thermoreflectance experiments. J Appl Phys 111:084313

[26] Frétigny C, Roger JP, Reita V, Fournier D (2007) Analytical inversion of photothermal measurements: independent determination of the thermal conductivity and diffusivity of a conductive layer deposited on an insulating substrate. J Appl Phys 102:116104

[27] Li B, Roger JP, Pottier L, Fournier D (1999) Complete thermal characterization of film-on-substrate system by modulated thermoreflectance microscopy and multiparameter fitting. J Appl Phys 86:5314-5316

[28] Pottier L (1994) Micrometer scale visualization of thermal waves by photoreflectance microscopy. Appl Phys Lett 64:1618-1619

[29] Tureson N, Marteau M, Cabioch T, Van Nong N, Jensen J, Lu J, Greczynski G, Fournier D, Singh N, Soni A, Belliard L, Eklund P, le Febvrier A (2018) Effect of ion-implantationinduced defects and $\mathrm{Mg}$ dopants on the thermoelectric properties of ScN. Phys Rev B 98:205307

[30] Eklund P, Högberg H, Hultman L (2007) Epitaxial TiC/SiC multilayers, physica status solidi (RRL). Rapid Res Lett $1: 113-115$

[31] Božin ES, Sartbaeva A, Zheng H, Wells SA, Mitchell JF, Proffen T, Thorpe MF, Billinge SJL (2008) Structure of $\mathrm{CaMnO} 3$ in the range $10 \mathrm{~K} \leqslant \mathrm{~T} \leqslant 550 \mathrm{~K}$ from neutron timeof-flight total scattering. J Phys Chem Solids 69:2146-2150

[32] Ohtaki M, Koga H, Tokunaga T, Eguchi K, Arai H (1995) Electrical transport properties and high-temperature thermoelectric performance of (Ca0.9M0.1) MnO3 $(\mathrm{M}=\mathrm{Y}, \mathrm{La}$, Ce, Sm, In, Sn, Sb, Pb, Bi). J Solid State Chem 120:105-111

[33] Huang XY, Miyazaki Y, Kajitani T (2008) High temperature thermoelectric properties of $\mathrm{Ca} 1-\mathrm{xBixMn} 1-\mathrm{yV}$ yO3 $\delta(0 \leq \mathrm{x}=\mathrm{y} \leq 0.08)$. Solid State Commun 145:132-136
[34] Kabir R, Zhang TS, Wang DY, Donelson R, Tian RM, Tan TT, Li S (2014) Improvement in the thermoelectric properties of $\mathrm{CaMnO} 3$ perovskites by $\mathrm{W}$ doping. J Mater Sci 49:7522-7528. https://doi.org/10.1007/s10853-014-8459-x

[35] Snyder GJ, Toberer ES (2008) Complex thermoelectric materials. Nat Mater 7:105-114

[36] Karim DP, Aldred AT (1979) Localized level hopping transport in $\mathrm{La}(\mathrm{Sr}) \mathrm{Cr}$ 3. Phys. Rev. B 20:2255-2263

[37] Ohtaki M, Tokunaga T, Eguchi K, Arai H (1997) Hopping carrier mobilities and thermoelectric properties of oxide materials with perovskite-related structure. In: Proceedings ICT'97. 16th international conference on thermoelectrics (cat. no. 97TH8291), Dresden, pp 224-227. https://doi.org/ 10.1109/ICT.1997.667087

[38] Melo Jorge ME, Correia dos Santos A, Nunes MR (2001) Effects of synthesis method on stoichiometry, structure and electrical conductivity of $\mathrm{CaMnO} 3-\delta$. Int $\mathrm{J}$ Inorg Mater 3:915-921

[39] Zhou Q, Kennedy BJ (2006) Thermal expansion and structure of orthorhombic CaMnO3. J Phys Chem Solids 67:1595-1598

[40] Xu GJ, Funahashi R, Pu QR, Liu B, Tao RH, Wang GS, Ding ZJ (2004) High-temperature transport properties of $\mathrm{Nb}$ and $\mathrm{Ta}$ substituted $\mathrm{CaMnO} 3$ system. Solid State Ionics 171:147-151

[41] Zhu Y-H, Su W-B, Liu J, Zhou Y-C, Li J, Zhang X, Du Y, Wang C-L (2015) Effects of Dy and Yb co-doping on thermoelectric properties of $\mathrm{CaMnO} 3$ ceramics. Ceram Int 41:1535-1539

[42] Goldyreva EI, Leonidov IA, Patrakeev MV, Kozhevnikov VL (2013) Electron transport in $\mathrm{CaMnO} 3-\delta$ at elevated temperatures: a mobility analysis. J Solid State Electrochem 17:1449-1454

[43] Goldyreva EI, Leonidov IA, Patrakeev MV, Kozhevnikov VL (2014) Temperature activated electron transport in CaMnO3. Solid State Ionics 262:678-681

Publisher's Note Springer Nature remains neutral with regard to jurisdictional claims in published maps and institutional affiliations. 